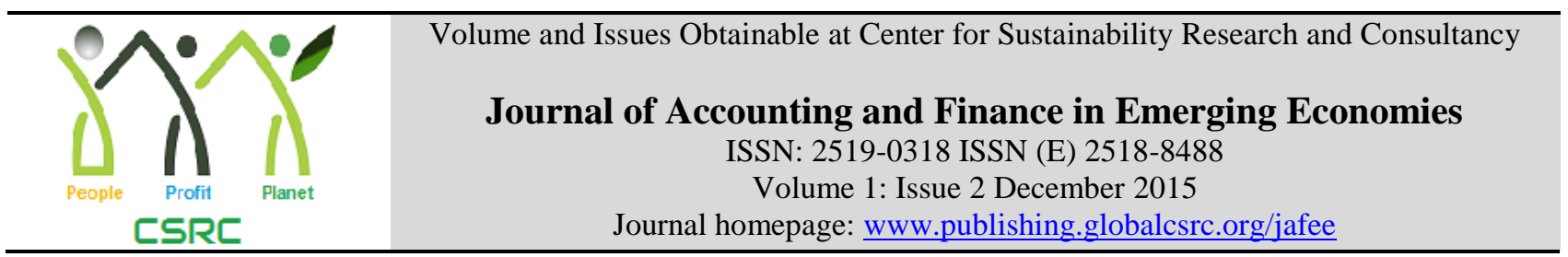

\title{
Quest for Alternative Sociological Perspectives on Corporate Social and Environmental Reporting
}

\author{
${ }^{1}$ Zeeshan Mahmood, ${ }^{2}$ Zubair Ahmad \\ ${ }^{1}$ Assistant Professor, Bahauddin Zakariya University Multan, Pakistan. zubairahmad@bzu.edu.pk \\ ${ }^{2}$ Assistant Professor, Bahauddin Zakariya University Multan, Pakistan. zeeshanmahmood@bzu.edu.pk
}

ARTICLE DETAILS
History
Revised Format Nov 2015
Available Online Dec 2015

Keywords
Legitimacy theory
Stakeholder theory
Institutional theory
Institutional logics perspective
Theory of realistic evaluation
Corporate social and
environmental reporting

JEL Classification:

C78, C79, K32

\begin{abstract}
Objective: The purpose of this paper is to review existing dominant theoretical perspectives used in corporate social and environmental accounting research, identify their limitations and to suggest some alternative theoretical perspectives for further research.

Methodology: In order to identify relevant research papers, on the use of different theoretical perspectives on corporate social and environmental accounting research, published in academic journals, different keywords were searched in google scholar. Research papers were then shortlisted according to their relevance to the topic.

The results: Among all theoretical frameworks, there is a great variety but accounting researchers remained selective in heir use of the theory and some other aspects of the theory remained unexplored. Apart from this narrow application, repeated application of same theories, especially legitimacy and stakeholder theory) provide very little additional insights.

\section{Implication:}

The dominant theoretical perspectives on CSER do not fully capture the complexity of the phenomenon. This situation demands researchers to explore alternative theoretical perspectives for better and insightful research. The main contribution of this paper is that it suggests the theory of realistic evaluation (RE) and the institutional logics perspective (ILP) as alternative sociological perspectives. This paper invites future researchers to apply these theoretical frameworks and to explore their usefulness.
\end{abstract}

(C) 2015 The authors, under a Creative Commons AttributionNonCommercial 4.0

Corresponding author's email address: zeeshanmahmood@bzu.edu.pk

Recommended citation: Mahmood, Z. and Ahmad, Z. (2015). Quest for Alternative Sociological Perspectives on Corporate Social and Environmental Reporting. Journal of Accounting and Finance in Emerging Economies. 1

(2) 135-152. DOI: https://doi.org/10.26710/jafee.v1i2.69

\section{Introduction}

Corporate social and environmental reporting (CSER) is a complex phenomenon due to the various 
complexities at "macro" or "political economic" level, "meso" or "organisational" level and 'micro' or individual level. Despite of these complexities very often research on CSER come up with various explanations without acknowledging these differing contexts at different levels. Moreover explanations are largely restricted to explaining social phenomena at the level of happenings (empirical level) without an attempt to go beyond that and trying to identify the mechanisms and structures which generate such happenings. This lack of breadth and depth in explanation limited our ability to understand/evaluate "why" and "how" CSER is done and what impact it is having towards organizational change for better social and environmental performance (Adams \& Whelan, 2009). This limited explanation ultimately impacts our ability to understand how change towards better social and environmental performance might occur which is the main desire of researchers in this field (Adams \& Larrinaga-González, 2007; R. Gray, 2002).

There is a need for diverse and in-depth explanations for CSER and their impact on social and environmental performance (Bebbington, Larrinaga, \& Moneva, 2008). Such explanation shall move from empirical level and takes into account the complexity of both external and internal context. Such explanation should also include the mechanisms that might lead organizations to report on their social and environmental issues (Adams, 2002). In this regard, there is a need for the use of more subtle theoretical lenses and methodologies so as to provide additional insights and to contribute towards theoretical understanding and development (Parker, 2005).

Extant research on CSER uses a very limited range of theoretical lenses. The vast majority of research uses legitimacy theory, stakeholders' theory and institutional theory as the main conceptual basis. This limited choice of theory has implications for the limited insights on CSER. The main aim of this paper is to review main theoretical perspectives used in the CSER field, identify their limitations and to suggest some alternative perspectives for future research. More specifically this paper suggests the Institutional Logics Perspective by and the theory of Realistic Evaluation by Pawson \& Tilley (1997) as alternative perspectives. The paper is organised into three main sections. First section presents the critical review of dominant sociological perspectives in CSER. Limitations are identified in second section which is followed by a section three which suggests two alternative perspectives.

\section{Dominant Perspectives on Corporate Social and Environmental Reporting}

R. Gray, Kouhy, \& Lavers (1995) has classified various theoretical perspectives on CSER into three groups - decision-usefulness studies, economic theory studies, social and political theory studies. However, according to them, theoretical perspectives drawn from social and political theory provide more interesting and insightful research. Therefore as the first departure point this review is only based social and political theory based perspectives. Three dominants theoretical perspectives that are used by researchers under this group include -legitimacy theory, stakeholders' theory and institutional theory. Legitimacy theory and stakeholders' theory is linked to political economy theory while institutional theory is linked to social theory (Deegan \& Unerman, 2011).

An important part of this review is the ability of these theoretical perspectives to capture the diverse and in-depth multi-level explanations for the phenomenon due to complexities at various levels. In recent categorisation of theories used in social accounting, Rob Gray, Owen, \& Adams (2010) used the notion of level of resolution and categorised different theories as meta-theories, meso-theories and microtheories. These three categories of theories differ in their level of resolution with meta-theories having low resolution while micro-theories provide higher resolution. In terms of their focus, the higher level is most abstract (abstracted from empirical conditions) while the low level is more specific than ground experience (Llewelyn, 2003). They argue that these different lenses will provide different understanding 
at different levels of resolution and no single lens can fully explain the phenomenon as it only captures a part of the picture either from the broad or narrow perspective. Based on these arguments, this review of theories will explore the explanatory potential and contribution of each of the theories. Specifically, it will look into the level of resolution a theory provides and whether the theory is capable of providing multi-level explanations and taking into account the complexity of external and internal contexts.

\subsection{Legitimacy Perspectives}

Legitimacy theory is the most widely used theoretical lens to explore why corporate managers initiate CSER and disclose particular items of social and environmental information (Deegan, 2007; Deegan \& Unerman, 2011; Owen, 2007). There are two main variants of legitimacy theory: institutional and strategic/instrumental (Deegan \& Unerman, 2011; Suchman, 1995). Institutional legitimacy goes back to the writings of DiMaggio \& Powell $(1983,1991)$ and emphasise more on cultural embeddedness than agency. Strategic/instrumental legitimacy goes back to the writings of Ashforth \& Gibbs (1990) and Dowling \& Pfeffer (1975) which emphasise more on agency. However, they shall be considered as two sides of the same coin (Suchman, 1995), or two levels of analysis (Tilling \& Tilt, 2010). The institutional view is outside-in (society looking in and imposing conditions) while the strategic view is inside-out (managers looking out and working to secure legitimacy).

Most of the research related to CSER tends to draw its understanding of legitimacy from the second variant and is largely built on its articulation by (Lindblom, 1994) in an unpublished paper presented in a CPA conference (R. Gray, et al., 1995; Parker, 2005). According to Lindblom (1994, p. 2), legitimacy is “... a condition or status which exists when an entity's value system is congruent with the value system of a larger social system of which the entity is a part. When a disparity, actual or potential, exists between the two values there is a threat to the entity's legitimacy". Legitimacy theorists argue that firms have a 'social contract' with the broader society and that they seek to achieve a 'fit' between their value system and that of society (Deegan, 2007; Deegan, Rankin, \& Tobin, 2002). Under legitimacy theory, CSER is "...understood to be motivated by a desire to demonstrate corporate conformity with societal expectations"(Owen, 2007, p. 247).

Legitimacy is perceived as a resource upon which organisation survival is dependent (Dowling \& Pfeffer, 1975; O'Donovan, 2002). Managers are considered to be the manipulator of that resource and if they perceive a legitimacy gap they try to regain this through legitimation strategies (Suchman, 1995). These legitimation strategies can be substantive and/or symbolic (Ashforth \& Gibbs, 1990) and vary depending upon whether an organisation is trying to gain, maintain or repair legitimacy (O'Donovan, 2002). These strategies include informing and educating an external audience, trying to change their perceptions, deflecting their attention to other issues, or trying to change their expectations (Lindblom, 1994). This means that communication, in the form of disclosure of information to 'relevant publics', is essential for influencing legitimacy. Therefore corporate disclosures and reporting can be considered as legitimising devices as part of these legitimation strategies (R. Gray, et al., 1995).

There are several studies that have found evidence that is consistent with this conceptualisation. These studies provide some useful insights about the managerial motivation of particular reporting and disclosure practices. For instance, Deegan (2002) found a linkage between unfavourable media attention and disclosure of environmental information. Similarly, Cho \& Patten (2007) suggest that firms with poor environmental performance or those operating in environmentally sensitive industries are more likely to disclose environmental information as a legitimising tool. There are a number of limitations of legitimacy theory. A number of researchers have contested the explanatory power of legitimacy theory. 
According to Adams (2002), legitimacy theory is limited due to the fact that it does not consider factors related to the social reporting processes as much as the attitudes of the agents. It does not explain how attitudes of agents are themselves shaped. It does not explain why different managers perceive legitimacy threats differently and are involved in different legitimation strategies (Deegan, 2002). Also, the "external audience" is portrayed as a homogenous group instead of being heterogeneous, with differences in interests and power (O’Dwyer, 2002) among various stakeholders.

Legitimacy theory is very much under-developed. In reality attitudes, priorities and institutions of corporate managers (as well as external audience) are guided by a complex range of internal and external factors that result in different ways of how they are motivated about the need for reporting and go about it. This has been confirmed by Adams (2002) in her study of the English and German firms in which she found internal factors to be extremely important in their influence on the quantity and quality as well as the scope of CSER in both countries. Apart from these limitations of the legitimacy theory, it has also been applied in a narrow fashion by accounting researchers. According to Mobus (2005), accounting literature emphasised the strategic conceptualisation of legitimacy which is narrow.

Altough the legitimacy theory as proposed by Suchman (1995) is well-devloped, the legitimacy theory framework of Lindblom (1994) still dominates the accounting research which is largely reactive in nature. Organsiations are suggests as conformists in that version of legitimacy theory (Guthrie \& Parker, 1989). Apart from some noticeable exceptions, legitimacy theory within accounting literature has been concerned largely with this reactive nature of organisational disclosure. The major emphasis of these studies has been on the attempts of the corporate managers to (re)build or repair legitimacy. In addition to this, these studies investigate legimatation as a reactive process and a short-term phenomenon (Tilling $\&$ Tilt, 2010). For better understanding of legitimacy dynamics, due consideration shall be given to both cultural embeddedness and an agential perspective which is missing from the literature.

\subsection{Stakeholder Perspectives}

Stakeholder theory is second frequently used theoretical lens in the CSERliterature. Stakeholder studies extended the work of Ullmann (1985) on relating the stakeholder perspective to CSER and disclosure. Stakeholder theory (Clarkson, 1995; Edward, 1984) is concerned with the effect of the environment on organisations. However, it does not consider the environment as a whole. It focuses on the relationship between organisations and its various stakeholders which constitute the environment (Berman, Wicks, Kotha, \& Jones, 1999; Chen \& Roberts, 2010). This relationship has two elements: stakeholders affecting firms and firms affecting stakeholders. These two elements are represented in two variants of stakeholder theory; normative ethical stakeholder theory which suggests the moral obligation of firms towards all stakeholders and instrumental stakeholder theory which suggests the strategic management of key stakeholders (Berman, et al., 1999).

Both variants of stakeholder theory are discussed in the CSER literature. In both variants, disclosure and reporting are seen as part of the dialogue between the company and its stakeholders (R. Gray, et al., 1995). From the normative (ethical) perspective, CSER can be seen as a mechanism to discharge accountability towards all stakeholders. From the instrumental (strategic) perspective CSER can be seen as a managerial tool or instrument to manage powerful stakeholders (Deegan, et al., 2002). Stakeholder demands ultimately infleunecs the decisions concerning the what to disclose and how to disclose in the sustainability reports. 
Empirical research has confirmed the role of stakeholders as an important determinant of social and environmental activities and disclosure (Roberts, 1992). Primary stakeholders were found to be concerned about the extent to which disclosure or non-disclosure leads to some effect on the financial returns either in the form of an increase in reputation or by gaining a competitive advantage. However, secondary stakeholders were found to place greater importance on CSER and want it to be transparent and are concerned with society and the environment (Tilt, 2007). The relative power of stakeholders was found to be an important determinant of sustainability disclosure (Roberts, 1992).

There is evidence that stakeholders put heterogeneous demands on organisations and some of them are likely to be conflicting and mutually exclusive. In the presence of these conflicting demands, managers determine the range of stakeholders and their demands they seek to address (Unerman, 2007). This choice is dependent on their motives of engaging in CSER. Stakeholder theory considers these motives to be either normative or instrumental. Through stakeholder perception studies, some researchers provide normative expectations of stakeholders in different contexts. In order to discharge accountability towards all stakeholders, which is considered to be the main motivation under the normative branch of stakeholder theory, actual practices should reflect these expectations. In contrast, researchers found different evidence that is more consistent with the predictions and explanations of instrumental stakeholder theory (Belal, 2002).

In an extensive stakeholders-based study, Belal \& Roberts (2010) found that disclosure practice in Bangladesh, opposite to the expectations of stakeholders, appear to be grounded in the normative perspective of stakeholders. They found that the current practice of reporting is largely a cosmetic response to pressures from the international market. These results are consistent with the results of some earlier studies. In an interview-based study of corporate managers in Bangladesh, Belal \& Owen (2007) reveal that the major motivation of managers for social reporting lies in a desire on the part of corporate management to manage powerful stakeholder groups. They also express concerns over the potential of such reporting towards accountability, especially when social standards are imposed from outside without consideration of local cultural, economic and social contexts. Similarly, Islam \& Deegan (2008), by applying stakeholder theory, find that operating and disclosure policies of the organisation under study reacted to the expectations of the multinational buying companies - the group deemed to be the most powerful.

Overall, stakeholder theory in CSER provides some useful insights in terms of highlighting the influence of powerful stakeholders, instrumental logic of managers and use of reporting as a tool to manage these powerful stakeholders. Much of these explanations (e.g. instrumental logic) can also be explained by legitimacy theory by lowering the level of resolution and considering society as a homogenous group. By specifying various stakeholders and how they influence reporting, stakeholder theory provides a better resolution. However, both of these theories provide insights into the presence of some sort of pressure and explain how these pressures are accommodated by companies in their reporting in a reactive way. As they focus on pressures, they focus on external factors while internal factors (like attitudes, priorities and institutions) of managers and stakeholders are ignored (Adams, 2002; Adams \& Whelan, 2009).

\subsection{Institutional Perspectives}

Sociological institutionalism comes in various forms. Of particular interest here are the neo-institutional theory perspective and the institutional entrepreneurship perspective that have been recently adopted in CSER studies (e.g. Etzion \& Ferraro, 2010; Larrinaga-Gonzalez, 2007). The two perspectives are 
different in terms of their emphasis on structure and agency. The neo-institutional theory perspective is more structural while the institutional entrepreneurship perspective is more agential.

Institutional accounts in the neo-institutional perspective are primarily concerned with the influence of broader social structures on social action. Institutions are understood to "comprise regulative, normative, and cultural-cognitive elements that, together with associated activities and resources, provide stability and meaning to social life" (Scott, 2008, p. 56). Institutional accounts question explanations based on rational actor models and instrumental rationality (Scott, 2008). There is a belief that "organizations and individuals who populate them are suspended in a web of values, norms, rules, beliefs, and taken for granted assumptions, that are at least partially of their own making" (Barley \& Tolbert, 1997, p. 93). These cultural elements (institutions) are in fact social constructions that stabilise over time and offer legitimate scripts for action (Berger \& Luckmann, 1967; Meyer \& Rowan, 1977; Scott, 2008). Institutions therefore set boundary on the rationality by putting constraints on the options that individuals and collectives are likely to exercise, thereby, increasing the probability of certain types of behaviour (Barley \& Tolbert, 1997). Managers conform to institutions - i.e. become isomorphic with their institutional context in order to increase chances of firms' survival as by conforming to social expectations they gain legitimacy - which is the central tenant of the institutional thinking (Scott, 2008).

According to DiMaggio and Powell (1983) isomorphism emerges through three mechanisms - coercive, normative and mimetic. Scott (2008) identified three types of institutional pillars - regulative, normative, and cultural-cognitive that represents the three mechanisms. The regulative pillar is based on the rule's setting, monitoring, recompense and punishment. Force, sanction and expedience are the central ingredients of the regulative pillar (Scott, 2008). This mechanism is usually exercised by powerful actors (e.g., the state, big customers, rating agencies) and pressures an organisation to adopt certain organisational practices (Greenwood et al., 2008). Such adoption is likely to be ceremonial and reflects a conscious and rational decision driven by the self-interest of an organisation in acquiring or maintaining resources (Higgins \& Larrinaga, 2014).

The normative pillar focuses on values and norms (Scott, 2008). Salient actors in the field socially construct normative expectations which include what is desirable for an organisation and how things should be done. These expectations become external pressures for an organisation which in turn adopts organisational practices with the main motivation to respect social obligations (Greenwood et al. 2008). Such adoption still reflect a conscious decision, however under normative pressures, the logic of appropriateness sets limits on this consciousness and possibility of instrumental behaviour (Scott, 2008).

Finally, under the cultural-cognitive pillar, activities are assumed to be enacted in relatively taken for granted ways. According to Scott (2008), the logic employed to justify conformity is that of orthodoxy, the perceived correctness and soundness of the ideas underlying action. Imitation is a cognition institution that better captures the isomorphic mechanism (DiMaggio and Powell, 1983). Organsiations imitate successful peers to gain legitimacy of the conventional acts. In case of conflicting prescriptions of institutional context and prescriptions of technical core of organizations, conformity may be ceremonial by decoupling symbolic practices from operations (Meyer \& Rowan, 1977; Zucker, 1987).

Institutional accounts mainly focus on the field-level and explain the process of how the social (institutional) context and pressures for social conformity shape organizational structures and practices. The concept of the field is central to the institutional studies which refers to the group of actors "that 
partake of a common meaning system and whose participants interact more frequently and fatefully with one another with actors outside the field" (Scott, 2008, p. 6). Fields can be "issue-based" (Hoffman, 1999) and may be considered as "socially constructed space arising from interactions, shared interest, and common concerns” (Rob Gray, et al., 2010).

The Organisational field defines the set of legitimate options for managers and constrains their discretion in the adoption of organisational practices (Hoffman, 1999). The process and the outcome of a process through which a practice becomes taken for granted in organisations is referred to as institutionalisation, which is the main focus of institutional studies (Larrinaga-Gonzalez, 2007). For instance, by now a corporate focus on sustainability "has become a strongly institutionalised feature of the contemporary corporate landscape in advanced industrial economies. The idea that corporations should engage in some form of responsible behaviour has become a legitimate expectation"(Brammer, Jackson, \& Matten, 2012, p. 10).

Institutional studies are largely unexplored in the area of CSER. However, in recent years, both structural and agential studies started to surface and add to the literature. Using the neo-institutional theory perspective, one line of work has explained the rise of CSER due to institutional pressures on organisations leading towards isomorphism. CSER may be initiated by managers to 'fit in' and to act 'appropriately' in the context in which they operate. This has been the main argument of LarrinagaGonzalez (2007) for the convergence of CSER among firms. According to him, CSER could become institutionalised through regulative, normative and cognitive institutional pressures, determining to some extent the choice of organisations in terms of whether or not to publish and report. Thus, CSER can be viewed as a response to regulation and/or a response to voluntary initiatives on the grounds of social responsibility and/or as a mimetic pressure to follow the orthodoxy in fields. This has been confirmed by Bebbington, Higgins, \& Frame (2009) in their interview-based study of early reporters in New Zealand. They analysed and demonstrated the influence of coercive, normative and cultural-cognitive pressures that interact with various organisational conditions to shape CSER as an 'appropriate' 'normal' activity or 'the right thing to do'.

Another line of work on CSER uses insights from the institutional entrepreneurship perspective and focuses strategic agency, rather than isomorphic forces leading to conformity and stability. For instance, Brown, De Jong, \& Lessidrenska (2009) studied the institutionalisation of the guidelines of the GRI and showed how through a combination of discursive, material (resource-based) and charismatic tactics, GRI managed to institutionalise CSER. The study of Levy, Brown, \& De Jong (2010) found similar results by emphasising field-level power relations. Similarly, Etzion \& Ferraro (2010) looked at the role of analogies as a mechanism guiding the institutionalisation of CSER.

Overall, institutional perspectives provide useful lenses through which the institutionalisation process of CSER may be viewed as an assemblage of external and internal factors (Adams \& Larrinaga-González, 2007). Institutional perspectives are richer than legitimacy and stakeholder perspectives in terms of their explanation (Deegan \& Unerman, 2011). It provides a complementary and partially overlapping, perspective to both legitimacy theory and stakeholder theory. The regulative pillar of institutional theory overlaps with the legitimacy and stakeholder theory that assumes a manipulative logic and power differences between various actors (Deegan, 2007; Higgins \& Larrinaga, 2014). However, institutional theory, complements this through different motives to be explored, which are primarily based on the logic of appropriateness and on the social construction of reality (Larrinaga-Gonzalez, 2007). 
Institutional theory expands legitimacy and stakeholder perspectives (Deegan, 2002, 2007), downplays managerial agency and consider a more complex range of factors that influence reporting and disclosure practices rather than deliberate decision-making (Bebbington, et al., 2009). Managers conform to societal expectations of the actors in the organisational field to safeguard organisational success and survival (Meyer \& Rowan, 1977) a view that is consistent with legitimacy theory and stakeholder theory. But this is not the only mechanism; other mechanisms can also shape this process of conformity and institutionalisation. It explains that managers will be subject to a combination of coercive, mimetic and/or normative pressures to change, or adopt, certain voluntary corporate reporting practices (Deegan \& Unerman, 2011).

The two institutional perspectives, however, are skewed and explain CSER as either an institutional outcome or the result of strategic agency of few individuals. The structural isomorphic studies limit their attention on the macro institutional environment and therefore portray organisations as conformists responding to external pressures. The main emphasis has been on the constraining nature of institutionalised beliefs and values (Dillard, Rigsby, \& Goodman, 2004). This has limited its explanatory potential as studies have tended to overlook the active role of agency and other dynamics in the process of institutionalisation (Dillard, et al., 2004; Lounsbury, 2008).

By focusing on the homogeneity of structures and practices, institutional theory ignores the heterogeneity of structure and practice variation (Lounsbury, 2008; P.H. Thornton, et al., 2012). While explaining the institutional dynamics, organisational and individual dynamics are largely ignored (Oliver, 1991). According to Greenwood \& Hinings (1996), internal organisational dynamics is an important determinant of organisational responses to external institutional pressures. In the words of (Bebbington, et al., 2009, p. 616), "what goes on inside organizations is as important as what goes on outside organizations to the institutional process". This highlights the need for institutional studies that attach importance to the role of social actors (organisations and individuals) in the process of institutionalisation.

Agential institutional entrepreneurship studies, on the other hand, give too much power to individuals and ignore the role of social structures shaping interest and power of agents. Institutional entrepreneurs are characterised as agents who can dis-embed themselves from existing institutional arrangements and can extend their self-interest to create new institutions or shape existing ones by deploying the resources at their disposal to create and empower institutions (Dacin, Goodstein, \& Scott, 2002; Hardy \& Maguire, 2008; Leca \& Naccache, 2006). They can manipulate cultural symbols and practices by story-telling and rhetorical strategies (P.H. Thornton, et al., 2012). This ability of institutional entrepreneurs to freely manipulate institutions has been criticised as it gives too much power to individuals (Hardy \& Maguire, 2008) and fails to answer how institutional entrepreneurs discover their ideas and self-interest and whether these ideas and interests are embedded in, or are autonomous from, the social system (P.H. Thornton, et al., 2012). In a nutshell, entrepreneurship studies overplayed the strategic and rational intentions of the institutional entrepreneurs at the expense of unintended consequences and the embeddedness of actors in their institutional contexts.

\subsection{Limitations of the Dominant Perspectives}

All three dominant theoretical frameworks (legitimacy, stakeholders and institutional theory) are complementary and partially overlapping. However, these theoretical frameworks differ in terms of their level of resolution (i.e. breadth and depth). Some are good in providing macro level explanations while 
some are good in providing meso and micro level explanations. There is lack of theoretical perspective that can provide multi-level explanation of the phenomenon.

Among all theoretical frameworks there is a great variety but accounting researchers remain selective in their use of the theory and some other aspects of the theory remained unexplored. A part from this narrow application, repeated application of same theories especially legitimacy and stakeholders theory) provide very little additional insights.

Explanatory potential of legitimacy theory is limited as it does not consider factors related to reporting processes as much as the attitudes of agents. Although the theory is perception based it does not explain how these perceptions are themselves shaped. Simply saying that managers are guided by their selfinterest and instrumentally use reporting to seek legitimacy of society is not enough. In reality attitudes, priorities and institutions of corporate managers are guided by complex range of internal and external factors that result in different ways how they are motivated about the need for reporting and go about it.

Stakeholders' theory provides better picture by specifying various stakeholders and how they influence reporting. However, like legitimacy theory, stakeholder theory also ignores the process and focus only on outcomes. It provides little explanation of how stakeholders exert pressure on companies? What are the attitudes, institutions and priorities of these stakeholders and how these are developed? How these different institutions are then aligned that appears as an outcome explained by instrumental stakeholder theory. Overall explanation lacks discussion of internal factors (like attitudes, priorities and institutions) of managers and their linkage to external factors.

Institutional theory provides a promising alternative as it explains process of institutionalisation. Institutional theory explains the process as the assemblage of external and internal factors. Institutional theory complements both stakeholder theory and legitimacy theory. Legitimacy theory and stakeholders theory assumes a manipulative logic, based on self-interest, which could correspond with coercive structures of institutional theory. However institutional theory also permits different motives (that correspond with normative and cognitive structures) to be explored: primarily based on the logic of appropriateness and on the social construction of reality. Its focus of analysis is more on the process of how the social context influences organisational participants to behave rather unconsciously in ways that are 'normal' to 'fit in' and appear 'appropriate' This illustrates that while managers still make conscious choices, under normative pressures, logic of appropriateness, replaces and sets limits on instrumental behaviour. The explanatory potential of institutional theory is also limited in terms of individual dynamics. Due to its main focus on macro institutional environment leading to structural conformity, institutional studies have tended to overlook the active role of agency and power dynamics in the process of institutionalisation. That is why it failed to explain practice variation as well as the impact of CSER on social and environmental performance. It failed to explain why some companies are reporting and some are not reporting? Why some companies are producing a separate report while others make it part of the annual report? Why some companies adopt standard guidelines while others do not follow any guidelines. Why some companies become members of international agreements (like UNGC) while others not? Organisations are portrayed as conformists responding to external pressures. If this is the case then in the presence of similar pressures all organisations shall respond in same way. However literature suggests that organisational dynamics and individual dynamics are also play an important role in the process of institutionalisation. Considering this active role of agency by focusing more on organisational and individual dynamics can provide some interesting and additional insights. Also such an analysis has the potential to provide multi-level explanations that takes into account complexity of 
both external and internal factors. Such an analysis is missing from the literature.

\subsection{Alternative Perspectives on Corporate Social and Environmental Reporting}

We suggest the use of the theory of realistic evaluation by Pawson \& Tilley (1997) and the Institutional Logics Perspective by P.H. Thornton, et al. (2012) as alternative perspectives on CSER. In our view these perspectives are capable of providing multi-level and in-depth explanation of "why" and "how" CSER is done and what impact it is having towards organisational change for better social and environmental performance. In this section these two perspectives are explained as well as some of their challenges and limitations.

\subsection{Theory of Realistic Evaluation}

The theory of realistic evaluation stresses the need to evaluate things within their "context" (Pedersen \& Rieper, 2008) and provides a broad conceptual framework (CMO framework) for putting underlying causal mechanisms at centre stage. The central proposition in the CMO framework is that the outcome (O) of an intervention/program (for instance CSER in this case) depends on how the underlying causal mechanisms (M) are fired in a specific context (C). Mechanisms link input (social and environmental reporting) and outcome (social and environmental performance), as they are triggered in certain contexts (external and internal). Outcomes may be positive or negative, intended or un-intended. It is the job of the researcher to formulate and test explanatory hypothesis on how a programme generates social change and to identify the context influencing the operation of these, in order to produce knowledge on what works, for whom, in which circumstances and how? Thus the aim of realistic evaluation is to accumulate knowledge, which can be useful in social programmes. Aim is to build middle-range theory, e.g. 'families' of CMO configurations, which provide knowledge on how social mechanisms creates change and produce outcomes in specific contexts (Marchal, van Belle, van Olmen, Hoerée, \& Kegels, 2012; R. Pawson \& Tilley, 1997; Stame, 2004).

... the basic idea of middle-range theory is that these propositions do not have to be developed de novo on the basis of local wisdom in each investigation. Rather they are likely to have a common thread running through them traceable to [a] more abstract analytic frameworks [. . .]. (R. Pawson \& Tilley, $1997: 123-4)$.

The major assumption in realistic evaluation is that all social programs (sustainability reporting in this case) are 'theories incarnate'. The theory may or may not be explicit (Manzano-Santaella, 2011; Millar, Powell, \& Dixon, 2012) but whenever a program is implemented, it is testing a theory about 'what might cause change'. In that sense one of the major task of realist evaluation is to make theories within program explicit (Millar et al., 2012), by developing various configurations about how, for whom and in what context programmes might work and then test those configurations by collecting data from the implementation of a programme in specific contexts. This is expected to result in testing previous theories and developing a new one and help policy makers to make well informed policies (R. Pawson \& Tilley, 1997).

Theory of realistic evaluation has its roots in a philosophy called scientific realism which shares common ground with critical realism (Marchal et al., 2012). It accepts that there is a real world 'out there' that exists independently of the researcher (natural realism) but this reality cannot be directly and empirically observed without any mediation. It follows the relativist epistemology as knowing the reality through science is unavoidably relative to the researcher (Sayer, 2000). Realist evaluators believe 
in generative nature of causality and the potential of actors for change. Realists accepts the role of agency, however at the same time they gave independent status to the structural and institutional conditions (R. Pawson \& Tilley, 1997). As a result of the interplay between institutions and individuals, both actors as well as social programmes have their roots in stratified social reality. This means that causal mechanism are placed in social relations and institutional context as well as among individuals The main aim of realists is to explore such causal mechanisms (M), residing at institutional and individual levels, that combinse with a specific context $(\mathrm{C})$ to create change that can be observed in the form of outcomes $(\mathrm{O})$, commonly known as CMO configuration.

The concept of CMO configurations as explained by R. Pawson and Tilley (1997) is best considered as a way of operationalizing this philosophy (Harrison \& Easton, 2004). Moreover this theory also provides guidance for research design to ensure realisation of research objectives.In practice, realistic evaluation start with middle range theory (MRT) and end with refined MRT (R. Pawson \& Tilley, 1997 : 84). Existing theory, past experience and previous evaluations or research studies results in the formulation of the initial MRT. In this way it provides a basis to systematically organise literature review to come up with initial MRT. After initial MRT from literature review, field study is designed to ensure that data collection and analysis tools are developed to enable testing of the elements of MRT. CMO configurations are used as the main imaging tool and mixed methods can be used. Resulting explanations are formulated as conjectured CMO configurations that may be in the form of narrative summaries, tables or diagrams. Finally they are translated into more abstract level of MRT which is modified if necessary.

Conducting research in this way aids the evaluation of complex issues as it not only exposes the underlying causal mechanism but also exposes the influence of the context responsible for firing/miss firing the mechanism (Greenhalgh et al., 2009). It helps in understanding change in the form of intermediate processes between actions and outcomes. This understanding enhances the transferability of findings to other setting (Weiss, 1997). Research is more relevant to practice and policy makers (Stame, 2004). It increases the general knowledge base as it provides incremental knowledge by framing findings on existing theories (Ray Pawson, 2003). However a number of challenges and limitations are identified in the literature by many researchers. Awareness of those challenges and limitations and how they might affect research is an important consideration while selecting a theoretical framework.

Marchal et al. (2012) in their literature review of realist evaluation in health systems identified three main challenges. First there may be little or no relevant theory to the problem under consideration. Second challenge is to identify what constitute a "mechanism" and "context". Despite of the guidance provided by R. Pawson and Tilley (1997) about what constitute as a "mechanism" and "context", there is a risk that these terms are interpreted in a narrow fashion as confirmed by Astbury and Leeuw (2010) and Barnes, Matka, and Sullivan (2003). This challenge is further increased by the fact that in the field of accounting, "mechanism" and "context" based explanations are scarce. Further as theory of realistic evaluation is not used so far in accounting, so it poses a great challenge to interpret the concepts of the theory properly and apply them to accounting. But at the same time this could be the major contribution in the field of accounting and to the theory in itself. Final challenge is the availability of time and resources as such evaluations can be resource and time consuming.

For many researchers realistic evaluation is well suited to investigate the complexity, either for evaluating complex programs or of complex causal pathways. However for some researchers, in practice it is very difficult to do for complicated, multi-component interventions taking place in different 
contexts. This poses some limitations of multiplicity of context and mechanism. Byng, Norman, and Redfern (2005) in their research highlight these limitations. According to them this theory ignores the possibility of multiple competing mechanisms and feedback loops between outcomes of an intervention and the original mechanisms. According to them both of these issued are much considered by Bhaskar (1989) and these limitations may affect the way in which mechanism may be analysed. Considering them in the research design may result in better explanation and theoretical development. This hinted towards the fact that that the principles of critical realism on which realistic evaluation is built are applied to varying degrees and its awareness may help researcher to work on limitations and contribute to the theory development. Despite of this, realistic evaluation provides a sound framework to examine how context and mechanism bring change and even the superficial application of realistic evaluation to the field of CSER has the advantage of exploring the processes and context which is lacking and required for advancement in the field.

\subsection{The Institutional Logics Perspective}

P.H. Thornton, et al. (2012, p. 2), describe the ILP as a "meta theoretical framework for analysing the interrelationships among institutions, individuals, and organisations in social systems". The ILP aids the researcher in exploring how individuals and organisations shape, and are being shaped by, their institutional environment. According to Cloutier \& Langley (2013), the ILP is a useful and practical lens through which to account for the plurality of norms and beliefs in institutional theory and for explaining the processes underscoring institutional formation and change. The ILP follows a broad meta-theory: "to understand individual and organisational behaviour, it must be located in a social and institutional context, and this institutional context both regularizes behaviour and provides opportunity for agency and change" (P.H. Thornton \& Ocasio, 2008, p. 102). There are five fundamental principles that underline this meta-theory: society as an inter-institutional system, partial autonomy of social structure and action, institutions as material and symbolic, institutions as historically contingent, and institutions at multiple levels of analysis (Friedland \& Alford, 1991; P.H. Thornton \& Ocasio, 2008; P.H. Thornton, et al., 2012).

The most comprehensive theoretical framework in the ILP is the "inter-institutional system" which is made up of seven institutional orders of market, corporation, profession, state, family, religion and community, all theorised, across nine categories that collectively constitute logics of these institutional orders (P.H. Thornton, et al., 2012, p. 73). Institutional orders can be understood as mega institutions (or societal orders) that can be found in a particular society. These mega institutions are guided and organised by their distinct rationality or institutional logics. Institutional logics are "socially constructed, historical patterns of cultural symbols and material practices, including assumptions, values, and beliefs, by which individuals and organisations provide meaning to their daily activity, organize time and space, and reproduce their lives and experiences" (P.H. Thornton, et al., 2012, p. 51). Institutional logics are more abstract and powerful social structures than are institutions - they make and guide the institutions (Johansen \& Waldorff, 2015). Institutional logics are a set of material practices and symbolic constructions guiding the institution. Institutional logics shape individual interests and preferences, and provide rationality and vocabularies for motives to attain those interests and preferences.

Being part of a social system, organisations and individuals are under the influence of institutional orders and their underlying logics. Each order represents a different set of expectations (logics) and can shape in different ways how rationality for action is perceived and experienced. This means that rationality varies with the institutional order and there can be multiple institutionally-based rationalities 
in a given context (Lounsbury, 2008) which may lead to different actions by providing a different reference system for such action (Goodrick \& Reay, 2011). In this way the ILP differs from the neoinstitutional theory which assumes a binary (rational-technical vs. non-rational-institutional) view of rationality (P.H. Thornton, et al., 2012).

Looking from the institutional logics perspective, CSER is an institution which is socially constructed by subjects (practitioners) through constellations of subjective meanings and material practices (known as institutional logics). CSER is an institution which one believes to "exist", which one "prepares", "publishes", and "reads" and through which one can "discharge accountability", "show responsibility" and "obtain benefits". CSER is pointed to, evoked, and known through particular categories (e.g. efficiency, transparency) enacted through particular sets of material practices (e.g. stakeholder engagement, materiality analysis, publishing standalone reports) which are experienced through a particular form of subjectivity in the form of beliefs about its needs and benefits. Publication of a report is the tangible form of the belief about its existence and about the need and benefit of CSER. These beliefs then shape reporting practices. For example, the need for accountability would result in different forms of reporting while the need for creating value (which depends on how value is socially constructed) would result in other forms of reporting.

The ILP assumes that institutional logics manifest at multiple levels and that individual actors are nested in higher order levels - organisational, field, and societal. At the societal level, the ILP illustrates seven distinct institutional orders and associated logics. The instantiations of logics within the field, organisations and individuals draw from and are nested within these societal level logics (Besharov \& Smith, 2014). For example, Patricia H Thornton (2002), in her study of higher education publishing, describes the industry's 'editorial' and 'market' logics as the instantiation of societal level 'professional' and 'market' logics. In this way, this meta-theoretical principle provides an opportunity to develop theory and research across multiple levels of analysis (P.H. Thornton, et al., 2012, p. 13). In short societal-logics, depending upon their instantiation by organisations and individuals, have implications in the emergence of field-level logics and practices. Field-level logics are both constrained and enabled by societal-logics.

The field in the ILP is the constellation of subjectivities and material practices related to the institution. Here, the field is "made up of a variety of organisations that have their values anchored in different societal-level institutional orders" (P.H. Thornton, et al., 2012, p.44). For example, $\operatorname{madrasas}^{1}$ (religion), private schools (market and corporation), public schools (state), not-for-profit schools (community), ministry of education (state), teachers (profession), parents (family) and school associations, all have huge stakes in the provision of education. These social actors interact with each other and take one another into account for the development of practices within and across organisations. The fact that these organisations are anchored in different institutional orders means that multiple logics exist at the field-level providing multiple forms of institutionally based rationalities (subjectivities) to the field participants. Therefore in essence, the field serves as the socially constructed space arising from interactions among organisations (Wooten \& Hoffman, 2008) where "multiple rationalities" (P.H. Thornton \& Ocasio, 2008) exist and where "collective rationality" (Scott, 2008) is constructed around specific issues (Hoffman, 1999) through communication, contestation and coordination. Such a conceptualisation of the field allows an institutional analysis that can provide insights into the heterogeneity of the context and its implications for organisational practices (Lounsbury, 2008).

\footnotetext{
${ }^{1}$ Madrasa is the name for a school for religious studies.
} 
Social actors are the key for institutional analysis (P.H. Thornton, et al., 2012). Social actors are "carriers" which represent and give voice to institutional logics (Greenwood, Raynard, Kodeih, Micelotta, \& Lounsbury, 2011). In the process, social actors play an important role in shaping and being shaped by institutional logics (Pache \& Santos, 2013). A core premise of the ILP is that "the interests, identities, values, and assumptions of individuals and organisations are embedded within prevailing institutional logics" (P.H. Thornton, et al., 2012). However, instead of assuming a deterministic view of institutions, the ILP presupposes partial autonomy of individuals and organisations in any explanation of social action (P.H. Thornton \& Ocasio, 2008). According to this perspective, social action is institutionally constrained but not institutionally determined. Social actors play an important role. The ILP conceptualises social actors as "situated, embedded, and boundedly intentional" (P.H. Thornton, et al., 2012, p.89) individuals having partial autonomy. This conception of actors allows for both taken for granted behaviour, as well as agency and reflexivity.

P.H. Thornton, et al., (2012) note that understanding of the internal organisational dynamics is very important for organisational analysis as it mediates the effect of the institutional environment on organisational practices. Nonetheless, organisational-level analysis shall also consider the wider influences of various institutional logics, pressures and cues stemming from other organisations in the field (Lounsbury, 2008). Collectively these influences, pressures and cues are considered as part of the dynamics external to the organisation and are considered equally important by the ILP (P.H. Thornton, et al., 2012). In this way, the ILP gives due importance to both dynamics in order to provide a complete understanding of the institutional embeddedness and organisational action. According to the framework, organisations are embedded in fields that constitute the constellation of logics and appropriate practices. Organisations draw upon these logics and practices in order to construct legitimate practices. Depending upon organisational characteristics and experience and how they are situated, some logics are more accessible than others. These accessible logics and the way these are used by organisational actors shape organisational rationality and actions.

The ILP provides a more refined perspective compared to the other theoretical perspectives used in the literature: legitimacy theory, stakeholder theory, neo-institutional theory and the institutional entrepreneur perspective. The ILP differs from the outset in terms of its orientation on heterogeneity and practice variation as compared to other institutional perspectives which focus on homogeneity and isomorphism (P.H. Thornton \& Ocasio, 2008). Compared with the legitimacy theory, stakeholder theory and the other institutional theories reviewed sectiontwo; the ILP provided an excellent basis to account for and helped explain the emergence of a complex phenomenon. It paid special attention to the multiple levels (macro, meso and micro) and enables a more detailed account of institutional, organisational and individual dynamics.

The ILP provides the conceptual tool to understand the social construction process of CSER. The main tool is inter-institutional system which is a useful concept for understanding the higher level institutional beliefs that both enabled and constrained the symbolic constructions at lower levels. It helped in illuminating the heterogeneous nature of any society in terms of the evolution of different societal orders and their implications for different practices. This conceptualisation differs from legitimacy theory which considers society as a homogenous group and disregard important forces behind shaping practices in a particular field. On the other hand, while stakeholder theory considers the heterogeneous nature of society in the form of different stakeholders having heterogeneous demands, it falls short of revealing the macro forces behind heterogeneity of such stakeholder demands. For instance, the institutional order of the community and its underlying logics play an important role in shaping the demands of nongovernmental and/or other community organisations. This study, therefore, argued that such an 
understanding of the societal context is necessary to reveal the complexity of drivers for both the presence and absence of CSER.

The conceptualisation of the field as a constituent of the "variety of organisations that have their values anchored in different societal-level institutional orders" (P.H. Thornton, et al., 2012, p. 44) provided insights into heterogeneity of the field that showed implications for practice adoption, non-adoption and variation (Ansari, Fiss, \& Zajac, 2010; Lounsbury, 2008). The perspective assumes that different logics may be associated with different actors due to their embeddedness in different institutional orders (Reay \& Hinings, 2009). For example, accountants and environmentalists may be guided by different competing logics under the influence of the professional and community order. Such a conceptualisation helped in exposing competing and complementary logics that exist at the field-level and the role of actors in advancing them through communication, coordination and contestation. In this way, this lens is quite useful in answering questions being raised in recent institutional studies in the field of CSER in terms of the role of actors in shaping the CSER field and its influence on organisations.

The framework is also useful for revealing internal organisational dynamics (for instance organisational culture) in order to understand how these dynamics interplay with external dynamics and influence reporting practices. In this way, the theoretical framework deals with both the external and internal dynamics on the initiation of SR practices. On one hand, by focusing on the societal and field-level, it provided a foundation for the analysis of the external factors affecting SR practices. On the other hand, the importance of internal factors was also recognised in the form of organisational values, practices and identities.

The ILP is not without challenges as well as limitations. The challenges are mainly related to the concept of institutional logics and especially how it is theorised and operationalised. The concept of institutional logics is more or less an abstract theoretical concept which has been operationalised differently in empirical analysis. The definition of institutional logics is too open-ended and does not specify exactly what comprises a logic (Powell \& Bromley, 2013). The categorical elements in the form of ideal-types of institutional logics by P.H. Thornton, et al. (2012) are also not tightly defined. According to Cloutier \& Langley (2013), current conceptualisations of institutional logics have also ignored the moral (value) dimension which is an important explanatory mechanism for deepening our understanding of institutional and organisational dynamics. Values were given importance by Friedland \& Alford (1991) in their initial conceptualisation of institutions. The institutional system of P.H. Thornton, et al. (2012) represents values in a limited way by considering them as part of legitimacy. However, things are judged to be legitimate on the basis of conformity to institutions and not on the basis of their being right or wrong in a moral sense. In this way an important dimension is given less importance. Klein (2013) argues that even if social actors endorse one logic over the other, there has to be a moral dimension which pushes them to consider that some aspect of the status quo is "wrong" or "unfair".

\section{Conclusions}

The dominant theoretical perspectives on CSER do not fully capture the complexity of the phenomenon. They do not provide in-depth and multi-level explanation of why and how CSER is practiced and impact social and environmental performance. This situation demands researchers to explore alternative theoretical perspectives for better and insightful research. This paper critically reviewed the dominant theoretical perspectives and highlighted their limitations. The main contribution of this paper is that it 
suggests the theory of realistic evaluation (RE) and the institutional logics perspective (ILP) as alternative sociological perspectives. The theory of realistic evaluation stresses the need to evaluate things within their "context" and provides a broad conceptual framework (CMO framework) for putting underlying causal mechanisms at centre stage. Research based on RE is more relevant to practice and policy makers as it explains social mechanisms responsible for change towards better social and environmental performance. The ILP is a useful framework for multi-level analysis of the institutional logics and processual dynamics related to the emergence and development of CSER. It enables a more detailed account of the institutional, organisational and individual dynamics. The theoretical framework deals with both the external and internal dynamics on the initiation and institutionalisation of practices. The two theoretical perspectives are not without challenges and limitations which are also highlighted in this paper. Through this paper, we invite future researchers to apply these theoretical frameworks and to explore their usefulness.

\section{References}

Adams, C. A. (2002). Internal organisational factors influencing corporate social and ethical reporting: beyond current theorising. Accounting, Auditing \& Accountability Journal, 15(2), 223-250.

Adams, C. A., \& Larrinaga-González, C. (2007). Engaging with organisations in pursuit of improved sustainability accounting and performance. Accounting, Auditing \& Accountability Journal, 20(3), 333-355.

Adams, C. A., \& Whelan, G. (2009). Conceptualising future change in corporate sustainability reporting. Accounting, Auditing \& Accountability Journal, 22(1), 118-143.

Ansari, S. M., Fiss, P. C., \& Zajac, E. J. (2010). Made to fit: How practices vary as they diffuse. Academy of Management Review, 35(1), 67-92.

Ashforth, B. E., \& Gibbs, B. W. (1990). The double-edge of organizational legitimation. Organization science, 1(2), 177-194.

Barley, S. R., \& Tolbert, P. S. (1997). Institutionalization and structuration: Studying the links between action and institution. Organization studies, 18(1), 93-117.

Bebbington, J., Higgins, C., \& Frame, B. (2009). Initiating sustainable development reporting: evidence from New Zealand. Accounting, Auditing \& Accountability Journal, 22(4), 588-625.

Bebbington, J., Larrinaga, C., \& Moneva, J. M. (2008). Corporate social reporting and reputation risk management. Accounting, Auditing \& Accountability Journal, 21(3), 337-361.

Belal, A. R. (2002). Stakeholder accountability or stakeholder management: a review of UK firms' social and ethical accounting, auditing and reporting (SEAAR) practices. Corporate Social Responsibility and Environmental Management, 9(1), 8-25.

Belal, A. R., \& Owen, D. L. (2007). The views of corporate managers on the current state of, and future prospects for, social reporting in Bangladesh: An engagement-based study. Accounting, Auditing \& Accountability Journal, 20(3), 472-494.

Belal, A. R., \& Roberts, R. W. (2010). Stakeholders' Perceptions of Corporate Social Reporting in Bangladesh. Journal of business ethics, 97(2), 311-324.

Berger, P. L., \& Luckmann, T. (1967). The social construction of reality: New York: Doubleday.

Berman, S. L., Wicks, A. C., Kotha, S., \& Jones, T. M. (1999). Does stakeholder orientation matter? The relationship between stakeholder management models and firm financial performance. Academy of Management Journal, 488-506.

Besharov, M. L., \& Smith, W. K. (2014). Multiple institutional logics in organizations: Explaining their varied nature and implications. Academy of Management Review, 39(3), 364-381.

Brammer, S., Jackson, G., \& Matten, D. (2012). Corporate social responsibility and institutional theory: New perspectives on private governance. Socio-Economic Review, 10(1), 3-28. 
Brown, H. S., De Jong, M., \& Lessidrenska, T. (2009). The rise of the Global Reporting Initiative: a case of institutional entrepreneurship. Environmental Politics, 18(2), 182-200.

Chen, J. C., \& Roberts, R. W. (2010). Toward a More Coherent Understanding of the OrganizationSociety Relationship: A Theoretical Consideration for Social and Environmental Accounting Research. Journal of business ethics, 97(4), 651-665.

Cho, C. H., \& Patten, D. M. (2007). The role of environmental disclosures as tools of legitimacy: A research note. Accounting, Organizations and Society, 32(7), 639-647.

Clarkson, M. E. (1995). A stakeholder framework for analyzing and evaluating corporate social performance. Academy of management review, 20(1), 92-117.

Cloutier, C., \& Langley, A. (2013). The Logic of Institutional Logics Insights From French Pragmatist Sociology. Journal of Management Inquiry, 22(4), 360-380.

Dacin, M. T., Goodstein, J., \& Scott, W. R. (2002). Institutional theory and institutional change: Introduction to the special research forum. Academy of Management Journal, 45(1), 45-56.

Deegan, C. (2002). Introduction: The legitimising effect of social and environmental disclosures-a theoretical foundation. Accounting, Auditing \& Accountability Journal, 15(3), 282-311.

Deegan, C. (2007). Organisational legitimacy as a motive for sustainability reporting. In J. Unerman, J. Bebbington \& B. O'Dwyer (Eds.), Sustainability Accounting and Accountability: Routledge.

Deegan, C., Rankin, M., \& Tobin, J. (2002). An examination of the corporate social and environmental disclosures of BHP from 1983-1997: A test of legitimacy theory. Accounting, Auditing \& Accountability Journal, 15(3), 312-343.

Deegan, C., \& Unerman, J. (2011). Financial accounting theory: Second European Edition: McGrawHill Maidenhead.

Dillard, J. F., Rigsby, J. T., \& Goodman, C. (2004). The making and remaking of organization context: Duality and the institutionalization process. Accounting, Auditing \& Accountability Journal, 17(4), 506-542.

DiMaggio, P. J., \& Powell, W. W. (1983). The iron cage revisited: Institutional isomorphism and collective rationality in organizational fields. American sociological review, 147-160.

DiMaggio, P. J., \& Powell, W. W. (1991). The new institutionalism in organizational analysis: University of Chicago Press Chicago.

Dowling, J., \& Pfeffer, J. (1975). Organizational legitimacy: Social values and organizational behavior. Pacific sociological review, 122-136.

Edward, F. R. (1984). Strategic Management: a stakeholder approach. Boston: Pitman, 46.

Etzion, D., \& Ferraro, F. (2010). The role of analogy in the institutionalization of sustainability reporting. Organization Science, 21(5), 1092-1107.

Friedland, R., \& Alford, R. R. (1991). Bringing society back in: Symbols, practices and institutional contradictions. In W. W. Powell \& P. J. DiMaggio (Eds.), The New Institutionalism in Organisational Analysis (pp. pp. 232-263). Chicago, IL: University of Chicago Press.

Goodrick, E., \& Reay, T. (2011). Constellations of Institutional Logics: Changes in the Professional Work of Pharmacists. Work and Occupations, 38(3), 372-416. doi: 10.1177/0730888411406824

Gray, R. (2002). The social accounting project and Accounting Organizations and Society Privileging engagement, imaginings, new accountings and pragmatism over critique? Accounting, Organizations and Society, 27(7), 687-708.

Gray, R., Kouhy, R., \& Lavers, S. (1995). Corporate social and environmental reporting: a review of the literature and a longitudinal study of UK disclosure. Accounting, Auditing \& Accountability Journal, 8(2), 47-77.

Gray, R., Owen, D., \& Adams, C. (2010). Some theories for social accounting?: a review essay and a tentative pedagogic categorisation of theorisations around social accounting. In M. Freedman \& B. Jaggi (Eds.), Sustainability, Environmental Peformance and Disclosures (Vol. 4): Emarald Group Publishing Limited. 
Greenwood, R., \& Hinings, C. R. (1996). Understanding radical organizational change: Bringing together the old and the new institutionalism. Academy of Management Review, 21(4), 10221054.

Greenwood, R., Raynard, M., Kodeih, F., Micelotta, E. R., \& Lounsbury, M. (2011). Institutional complexity and organizational responses. The Academy of Management Annals, 5(1), 317-371.

Guthrie, J., \& Parker, L. D. (1989). Corporate social reporting: a rebuttal of legitimacy theory. Accounting and Business Research, 19(76), 343-352.

Hardy, C., \& Maguire, S. (2008). Institutional entrepreneurship. The Sage handbook of organizational institutionalism, 198-217.

Higgins, C., \& Larrinaga, C. (2014). Sustainability reporting Insights from Institutional Theory. In J. Bebbington, J. Unerman \& B. O'Dwyer (Eds.), Sustainability accounting and accountability (pp. 273-286): Routledge.

Hoffman, A. J. (1999). Institutional Evolution and Change: Environmentalism and the U.S. Chemical Industry. The Academy of Management Journal, 42(4), 351-371. doi: 10.2307/257008

Islam, M. A., \& Deegan, C. (2008). Motivations for an organisation within a developing country to report social responsibility information: Evidence from Bangladesh. Accounting, Auditing \& Accountability Journal, 21(6), 850-874.

Johansen, C. B., \& Waldorff, S. B. (2015). What are Institutional Logics - and where is the perspective taking us? Paper for the Academy of Management conference 2015.

Klein, V. H. (2013). Bringing values back in: The limitations of institutional logics and the relevance of dialectical phenomenology. Organization, 1350508413514786.

Larrinaga-Gonzalez, C. (2007). Sustainability Reporting: Insights from neoinstitutional theory. In J. Unerman, J. Bebbington \& B. O'Dwyer (Eds.), Sustainability Accounting and Accountability: Routledge.

Leca, B., \& Naccache, P. (2006). A critical realist approach to institutional entrepreneurship. Organization, 13(5), 627-651.

Levy, D. L., Brown, H. S., \& De Jong, M. (2010). The Contested politics of corporate governance the case of the global reporting initiative. Business \& Society, 49(1), 88-115.

Lindblom, C. (1994). The implications of organizational legitimacy for corporate social performance and disclosure. Paper presented at the Critical Perspectives on Accounting Conference, New York.

Llewelyn, S. (2003). What counts as "theory" in qualitative management and accounting research? Introducing five levels of theorizing. Accounting, Auditing \& Accountability Journal, 16(4), 662708.

Lounsbury, M. (2008). Institutional rationality and practice variation: New directions in the institutional analysis of practice. Accounting, Organizations and Society, 33(4), 349-361.

Meyer, J. W., \& Rowan, B. (1977). Institutionalized organizations: Formal structure as myth and ceremony. American journal of sociology, 340-363.

Mobus, J. L. (2005). Mandatory environmental disclosures in a legitimacy theory context. Accounting, Auditing \& Accountability Journal, 18(4), 492-517.

O'Donovan, G. (2002). Environmental disclosures in the annual report: extending the applicability and predictive power of legitimacy theory. Accounting, Auditing \& Accountability Journal, 15(3), 344-371.

O’Dwyer, B. (2002). Managerial perceptions of corporate social disclosure: an Irish story. Accounting, Auditing \& Accountability Journal, 15(3), 406-436.

Oliver, C. (1991). Strategic responses to institutional processes. Academy of management review, 145179.

Owen, D. (2007). Chronicles of wasted time?: A personal reflection on the current state of, and future prospects for, social and environmental accounting research. Accounting, Auditing \& 
Accountability Journal, 21(2), 240-267.

Pache, A.-C., \& Santos, F. (2013). Embedded in hybrid contexts: How individuals in organizations respond to competing institutional logics. Research in the Sociology of Organizations, 39, 3-35.

Parker, L. D. (2005). Social and environmental accountability research: a view from the commentary box. Accounting, Auditing \& Accountability Journal, 18(6), 842-860.

Pawson, R., \& Tilley, N. (1997). Realistic evaluation: Sage Publications Ltd.

Powell, W. W., \& Bromley, P. (2013). " New Institutionalism in the Analysis of Complex Organizations. Elsevier (Hg.): International Encyclopedia of Social and Behavioral Sciences, 2, $1-13$.

Reay, T., \& Hinings, C. R. (2009). Managing the rivalry of competing institutional logics. Organization Studies, 30(6), 629-652.

Roberts, R. W. (1992). Determinants of corporate social responsibility disclosure: an application of stakeholder theory. Accounting, Organizations and Society, 17(6), 595-612.

Scott, W. R. (2008). Institutions and organizations: Ideas and interests (3rd ed.): Sage Publications, Incorporated.

Suchman, M. C. (1995). Managing legitimacy: Strategic and institutional approaches. Academy of management review, 20(3), 571-610.

Thornton, P. H. (2002). The rise of the corporation in a craft industry: Conflict and conformity in institutional logics. Academy of Management Journal, 45(1), 81-101.

Thornton, P. H., \& Ocasio, W. (2008). Institutional logics. The Sage handbook of organizational institutionalism, 840.

Thornton, P. H., Ocasio, W., \& Lounsbury, M. (2012). The institutional logics perspective: A new approach to culture, structure, and process: OUP Oxford.

Tilling, M. V., \& Tilt, C. A. (2010). The edge of legitimacy: Voluntary social and environmental reporting in Rothmans' 1956-1999 annual reports. Accounting, Auditing \& Accountability Journal, 23(1), 55-81.

Tilt, C. A. (2007). External stakeholders' perspective on sustainability reporting. In J. Unerman, J. Bebbington \& B. O'Dwyer (Eds.), Sustainability accounting and accountability: Routledge London.

Ullmann, A. A. (1985). Data in search of a theory: a critical examination of the relationships among social performance, social disclosure, and economic performance of US firms. Academy of management review, 540-557.

Unerman, J. (2007). Stakehoder engagement and dialogue. In J. Unerman, J. Bebbington \& B. O'Dwyer (Eds.), Sustainability accounting and accountability: Routledge London.

Wooten, M., \& Hoffman, A. J. (2008). Organizational fields: Past, present and future. The Sage handbook of organizational institutionalism, 130-147.

Zucker, L. G. (1987). Institutional theories of organization. Annual review of sociology, 13, 443-464. 